\title{
PATOGÊNESE DA MIONECROSE EM PREPARAÇÕES DE DIAFRAGMA DE CAMUNDONGO INDUZIDA PELO VENENO BRUTO DA VESPA SOCIAL POLYBIA PAULISTA
}

\section{MYONECROSIS PATHOGENESIS INDUCED BY CRUDE VENON \\ OF THE SOCIAL WASP (POLYBIA PAULISTA) IN MOUSE DIAPHRAGM PREPARATIONS}

\author{
Márcia Regina Paes de Oliveira ${ }^{{ }^{*}}$, Alesandra Cristina Scheidt ${ }^{1}$ \\ 1* Autor para contato: Universidade Estadual de Ponta Grossa - UEPG, Departamento de \\ Biologia Estrutural, Molecular e Genética, Campus em Uvaranas, Ponta Grossa, PR, \\ Brasil; (42) 3220-3734; e-mail: marciarpaeso@ibest.com.br
}

Recebido para publicação em 07/05/2005

Aceito para publicação em 22/07/2005

\section{RESUMO}

Estudo sobre a patogênese da mionecrose induzida pelo veneno bruto da vespa social Polybia paulista foi realizado utilizando-se a microscopia de luz. Concentrações padronizadas do veneno bruto ( $20 \mu \mathrm{g} / \mathrm{g}$ de camundongo) foram injetadas intraperitonealmente em camundongos e após intervalos de tempo prédeterminado, estes foram sacrificados para a retirada do diafragma. A análise histopatológica evidenciou a presença de mionecrose do tipo miolítica, característica de venenos que possuem atividade fosfolipásica, sendo esta dividida em três estágios (inicial, intermediário e final) segundo as alterações morfológicas observadas. O estágio inicial ( 1 a 3 horas) caracterizou-se pela presença de lesões delta, miofibrilas densamente agrupadas e pequenos vacúolos. O estágio intermediário (6 a 24 horas) apresentou aumento no número de vacúolos que progrediram para áreas destituídas de organelas e aparência amorfa hialina, além de edema. O estágio final (48 a 72 horas) exibiu grande quantidade de células fagocíticas no local da lesão e algumas células contendo grânulos de heparina e histamina, que quando liberados induzem a alergia. O padrão das alterações morfológicas observadas nas fibras musculares durante o processo mionecrótico sugere que o efeito miotóxico é devido à atividade da fosfolipase, uma das principais enzimas presentes no veneno bruto da vespa em estudo (Paes-Oliveira, 2000).

Palavras-chave: veneno de vespa, mionecrose, fosfolipase $\mathrm{A}_{2}$, músculo estriado 


\begin{abstract}
This study about the myonecrosis pathogenesis induced by crude venom of the social wasp Polybia paulista was done with light microscopy examination. Standardised concentrations of the crude venom ( $20 \mu \mathrm{g} / \mathrm{g}$ of mouse) were intraperitoneally injected into mice, and after intervals of predetermined time these animals were sacrificed for the withdrawal of the diaphragm. The hystopathologic analysis evidenced the presence of myonecrosis, of the myolitic type, characteristic of venoms that present a phospholipasic activity, and which can be divided into three stages (initial, intermediate and final) according to the observed morphologic alterations. The initial stage of the experiment (from 1 to 3 hours) was characterized by the presence of delta lesions, densely clumped myofibrils and small clear vacuoles. The intermediate stage of the experiment (from 6 to 24 hours) presented increase in the number of vacuoles, that had progressed to areas destitute of organels and with a hyaline amorphous appearance and edema. The final stage of the experiment (from 48 to 72 hours) showed a great amount of phagocytic cells in the lesion and some cells presented granules of heparin and histamine that when liberated can induce allergy. The pattern of the morphologic alterations observed in muscle fibers during the myonecrotic process suggest that the myotoxic effect is due to the activity of phospholipase, one of the main enzymes found in crude venom of the wasp under study (Paes-Oliveira, 2000).
\end{abstract}

Key words: wasp venom, myonecrosis, phospholipase $\mathrm{A}_{2}$, skeletal muscle

\section{Introdução}

O veneno de vespa contém grande quantidade de compostos, incluindo proteínas (componentes de elevada massa molecular) com e sem atividade enzimática e peptídeos (componentes de baixa massa molecular).

Os principais componentes enzimáticos do veneno são: a hialuronidase que é considerada fator de difusão e a fosfolipase $A_{2}$, que provoca reações imunológicas intensas, inclusive a indução de hipersensibilidade em algumas pessoas (Dotimas e Hider, 1987). Dentre as proteínas não enzimáticas pode-se destacar a hornetina, isolada do veneno da Vespa flavitarsus, que apresenta atividade neurotóxica em preparações musculares do Biventer cervicis de pintainho e nervofrênico diafragma de camundongo (Ho e Ko, 1986) e a mandaratoxina, isolada da Vespa mandarinia, que atua na junção neuromuscular das pernas de lagosta (Abe et al., 1982).

Com relação aos componentes de baixa massa molecular, o veneno de vespa apresenta as cininas, substâncias envolvidas na produção de dor agindo especificamente em fibras musculares lisas; os mastoparanos, ricos em aminoácidos hidrofóbicos, que atuam na liberação de histamina em mastócitos do peritôneo de rato, causando a alergia, e os peptídeos quimiotácticos, compostos tridecapeptídeos de amida, que induzem a quimiotaxia em alguns tipos de células (Habermann, 1972). Yasuhara et al., 1984, relataram que os peptídeos quimiotácticos purificados do veneno da Vespa tropica induzem quimiotaxia em macrófagos e leucócitos polimorfonucleares.

As aminas biologicamente ativas também são encontradas no veneno de vespas. As mais comuns são a histamina, que dilata e aumenta a permeabilidade dos vasos sanguíneos facilitando a penetração de toxinas nos tecidos (Banks e Shipolini, 1986) e a serotonina, que também é considerada um agente difusor do veneno (Dotimas e Hider, 1987).

Sabendo-se que o veneno de $P$. paulista apresenta atividade miotóxica evidenciada pela mionecrose 
em preparações musculares do diafragma de camundongo (Paes-Oliveira, 2000), decidiu-se estudar, através da microscopia de luz, a dinâmica do processo mionecrótico e compará-lo com a mionecrose de outras etiologias.

\section{Materiais e métodos}

O veneno de $P$. paulista foi obtido através de dissecção manual das glândulas de veneno, solubilização em solução salina e centrifugação a 10.000RPM por 20 minutos a $4^{\circ} \mathrm{C}$.

Camundongos da linhagem Swiss (Mus musculus variedade albinus) fornecidos pelo Centro de Bioterismo da UNICAMP e mantidos em gaiolas com água e ração ad libitum, foram injetados intraperitonealmente com o veneno bruto de P. paulista $(20 \mu \mathrm{g} / \mathrm{g}$ de camundongo) e nos respectivos tempos (15 e 30 minutos; 1, 3, 6, 12, 24, 48 e 72 horas) após a injeção, os mesmos foram sacrificados através de secção e sangria dos vasos cervicais, imediatamente após serem anestesiados com hidrato de cloral ( $3 \mu \mathrm{g} / \mathrm{g}$ ). A quan-tidade de proteína presente no veneno bruto foi medida de acordo com o método de Lowry (Hartree, 1972), utilizando-se albumina de soro bovino como padrão. A retirada do diafragma de camundongo para a análise morfológica foi realizada utilizando-se a técnica descrita por Bülbring (1946), para ratos.

Preparações do diafragma obtidas nos respectivos tempos foram fixadas em Bouin por 24 horas e transferidas para tampão fosfato de sódio $0,1 \mathrm{M} \mathrm{pH}$ 7,4, desidratadas em soluções de etanol (70, 90, 95 e 100\%: 1 hora cada), seguida da infiltração do material em historesina Leyca até a sua polimerização. Secções com $3 \mu \mathrm{m}$ de espessura foram coradas com Azul de Toluidina $0,5 \%$. Preparações musculares controles

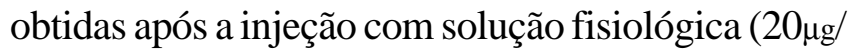
g) foram submetidas ao mesmo procedimento.

\section{Resultados}

O processo mionecrótico do tipo miolítico induzido pelo veneno de $P$. paulista pode ser dividido em estágios inicial, intermediário e tardio, de acordo com as características morfológicas observadas.

O estágio inicial ( 1 a 3 horas) caracteriza-se pela presença de lesões delta, miofibrilas densamente agrupadas e algumas células musculares apresentam pequenos vacúolos. Essas características morfológicas contrastam com a aparência normal das fibras musculares controle, que exibem forma poligonal, núcleos periféricos e perimísio íntegros (Figuras 1A, 1B e 1C) $(\mathrm{n}=4)$.

No estágio intermediário (6 a 24 horas) observase inicialmente o aumento na quantidade de vacúolos, que progridem para áreas destituídas de organelas. Posteriormente, a maioria das células musculares apresentam aparência amorfa hialina e massas miofibrilares degradadas. Ocorre ainda o aumento no diâmetro das fibras musculares, sugerindo ocorrência de edema. Após 24 horas, nota-se aumento significativo no número de células com aparência amorfa hialina e a presença de células fagocíticas (macrófagos) no endomísio (Figuras 2A, 2B e 2C) $(n=4)$.

O estágio tardio (48 a 72 horas) mostra a ocorrência de grande quantidade de células fagocíticas no endomísio e algumas fibras musculares com aparência amorfa hialina (Figuras 3A, 3B e 3C) $(n=4)$. 

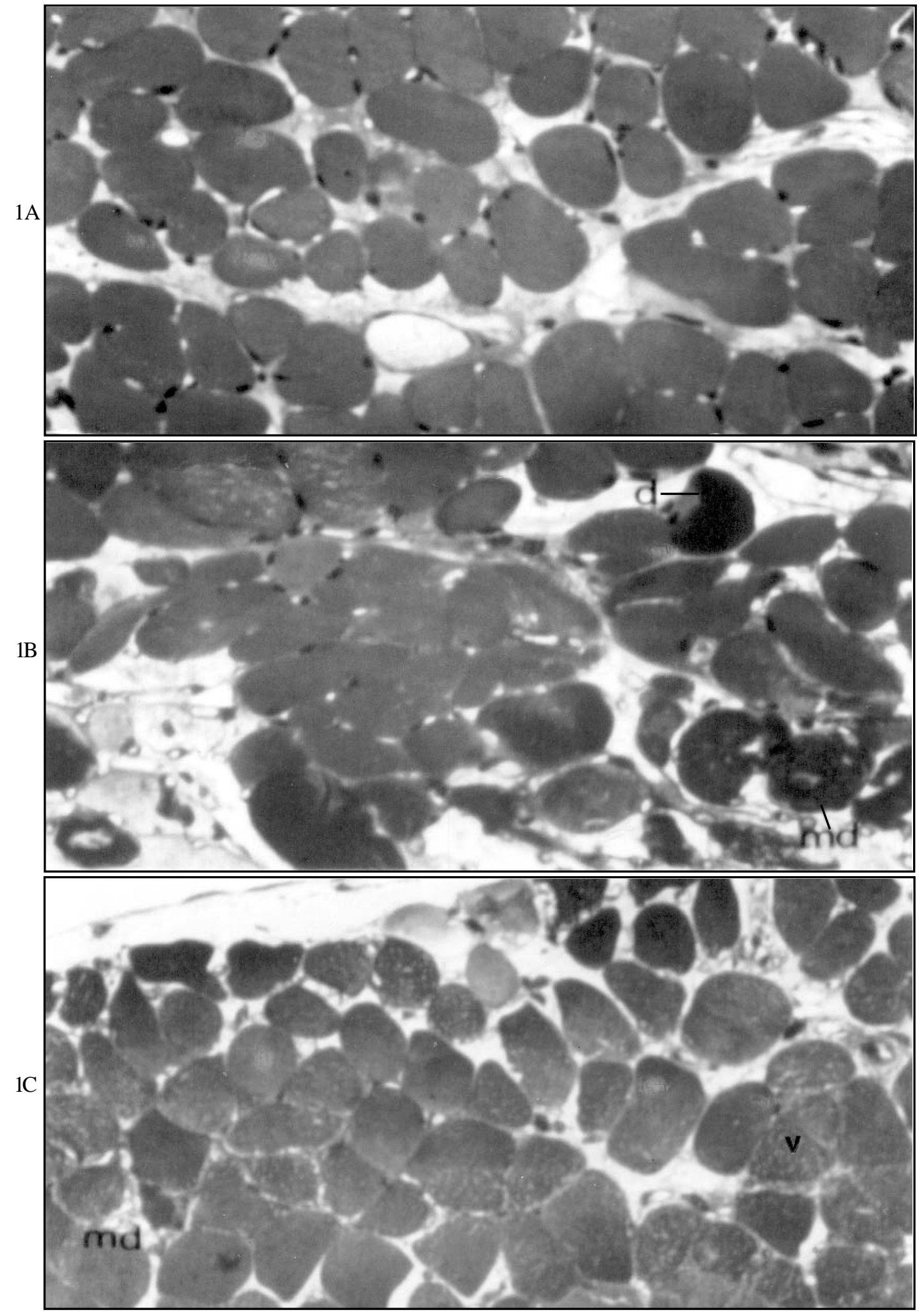

Figura 1 - Fotomicrografia em secção transversal do diafragma de camundongo controle e da fase inicial da mionecrose após a injeção de $20 \mu$ g do veneno de $P$. paulista.

(1A) Salina. Forma poligonal característica das fibras musculares normais; núcleos periféricos e perimísio íntegros. 210x

(1B) 1 hora. Presença de células musculares com lesões do tipo delta (d) e miofibrilas densamente agrupadas (md). 210x

(1C) 3 horas. Aumento de fibras musculares contendo vacúolos (v) e miofibrilas densamente agrupadas (md). 210x 

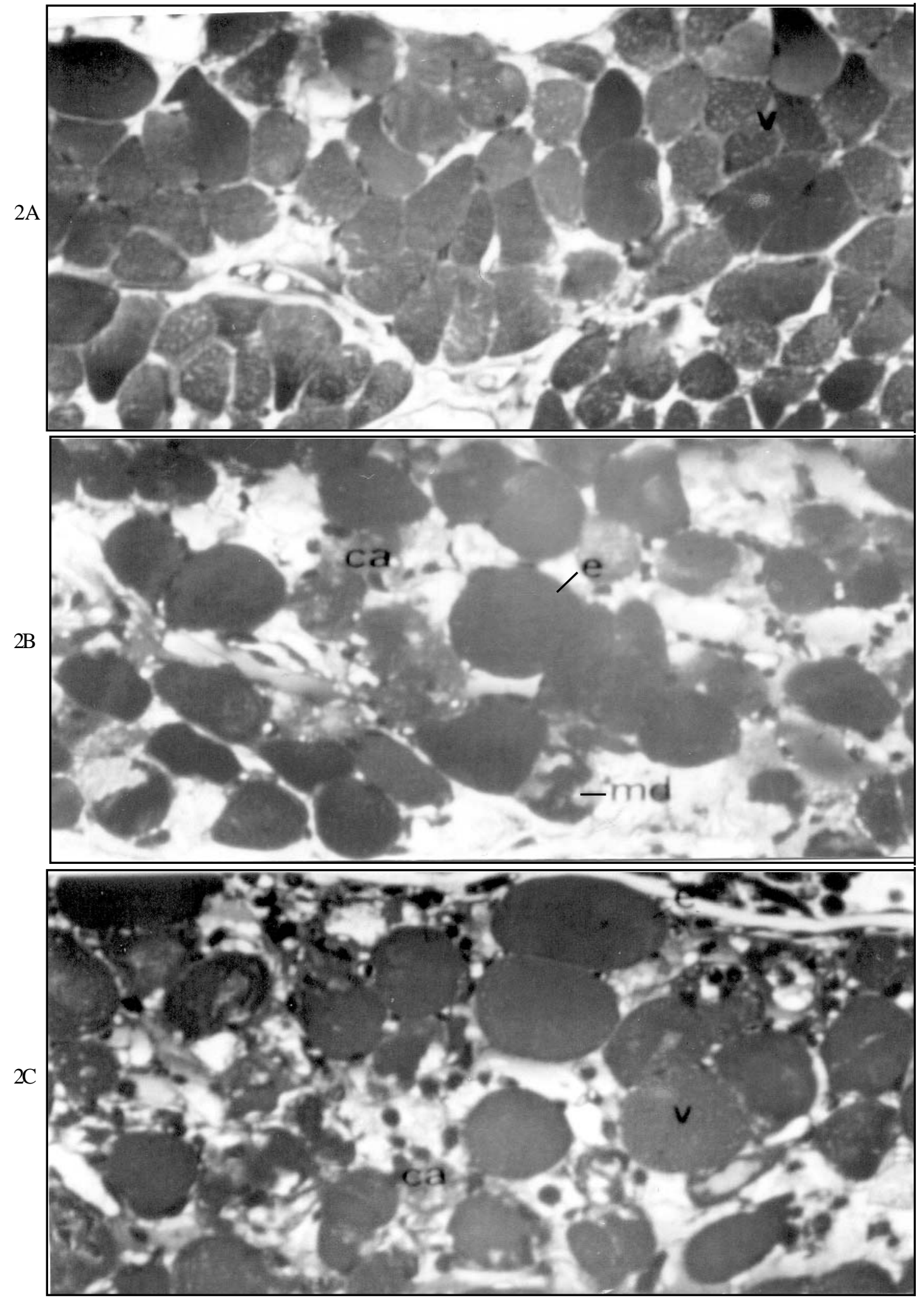

Figura 2 - Fotomicrografia da fase intermediária da mionecrose no diafragma de camundongo após a injeção de 20ug do veneno de $P$. paulista.

(2A) 6 horas. Elevada incidência de fibras musculares vacuoladas (v). 210x

(2B e 2C) 12 e 24horas. Presença de células musculares contendo vacúolos (v), miofibrilas densamente agrupadas (md) e aparência amorfa hialina (ca). Nota-se ainda células fagocíticas no endomísio. Atente para o aumento no diâmetro das fibras musculares sugerindo a ocorrência de edema (e). 210x 

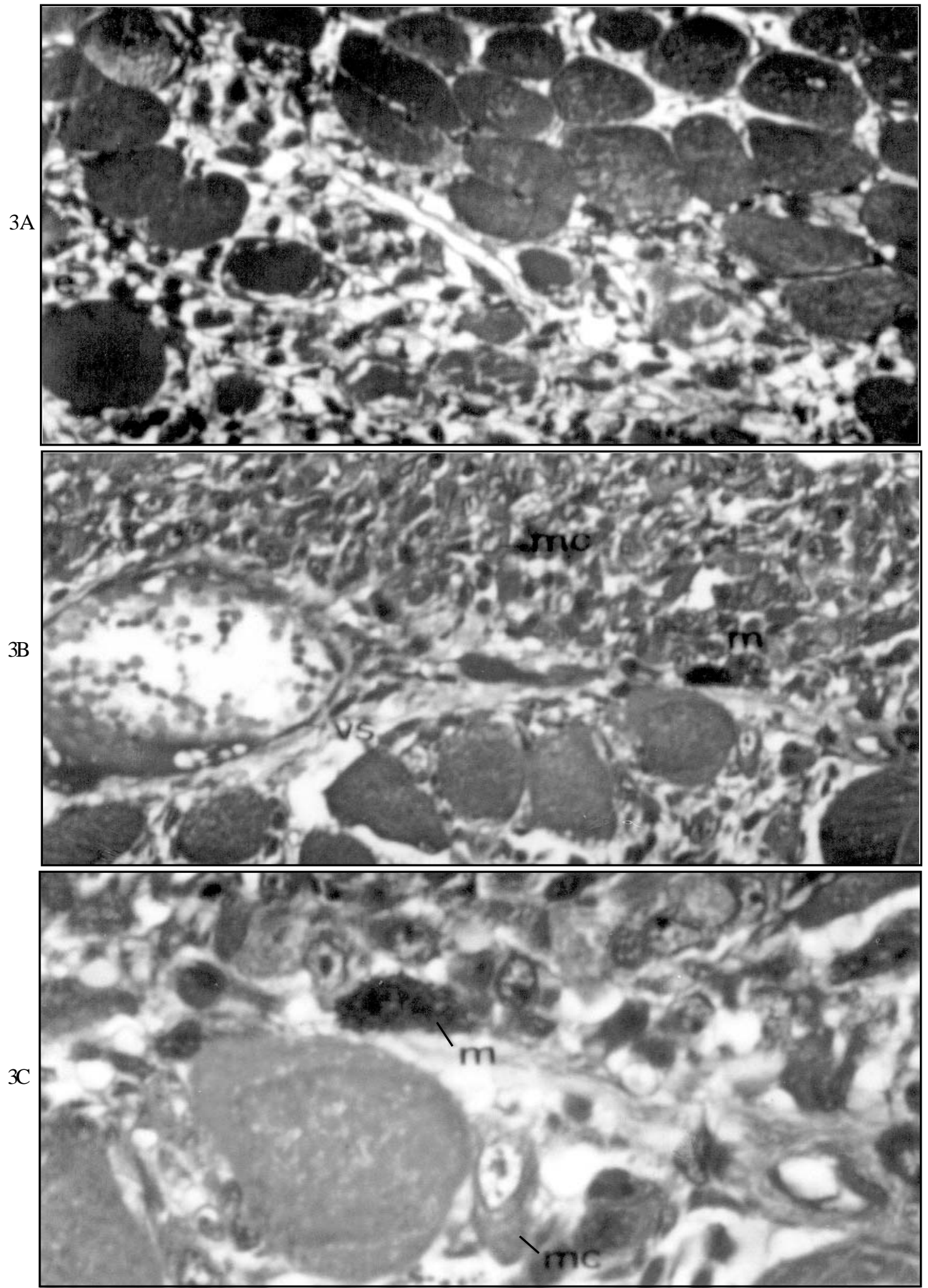

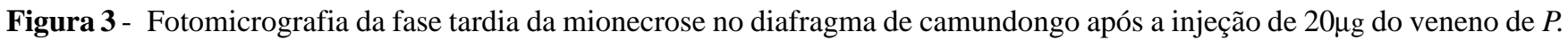
paulista.

(3A e 3B) 48 e 72 horas. Aumento significativo no número de células fagocíticas no endomísio (mc) e a permanência da aparência amorfa hialina em algumas fibras musculares. Presença de mastócito (m), célula conjuntiva que atua em processos inflamatórios, resultando na alergia. 210x

(3C) Detalhe 72 horas. Observação de mastócito (m) e macrógrafo (mc). 930x 


\section{Discussão e conclusão}

A mionecrose do tipo miolítica, causada pelo veneno de Polybia paulista, caracteriza-se pelo aparecimento de lesões delta que progridem para regiões de hipercontração e condensação das miofibrilas, alternando-se com espaços vazios no sarcoplasma decorrente do eventual relaxamento dos miofilamentos agrupados, sem a ocorrência de hemorragia, o que caracterizaria a mionecrose do tipo coagulativo descrita por Homa e Tu, 1971.

Segundo Duncan, 1978, a ocorrência de regiões de hipercontração e condensação das miofibrilas é decorrente do rápido e incontrolado influxo de cálcio e os espaços vazios entre as regiões de hipercontração e condensação de miofibrilas pode ser explicado através do enventual relaxamento das miofibrilas, possivelmente devido à ativação de proteases cálcio-dependentes.

A indução da mionecrose do tipo miolítica, em preparações do diafragma de camundongo, pelo veneno bruto de $P$. paulista já foi observada "in vitro" por Paes-Oliveira, 2000.

A análise "in vivo" do processo mionecrótico induzido pelo veneno da vespa em estudo evidenciou que a mionecrose pode ser dividida em estágios (inicial, intermediário e tardio) de acordo com as características histopatológicas, observadas em diferentes tempos após a injeção. A mionecrose do tipo miolítica já foi observada em algumas miotoxinas com atividade fosfolipásica, purificadas do veneno de serpentes, tais como, a notexina (Harris et al., 1975) e a crotoxina (Gopalakrishnakone et al., 1984). O mesmo tipo de mionecrose também já foi observado após a injeção do veneno bruto da serpente Micrurus nigrocinctus (Gutierrez et al., 1986) e das aranhas tarântulas Dugesiella hentzi e Aphonopelma spp (Ownby e Odell, 1983). Estudo realizado por Harris e Maltin, (1982), evidenciou que existem pelo menos dois tipos de toxinas no veneno de serpentes que causam a mionecrose: as fosfolipases e as cardiotoxinas. Este estudo permite sugerir que a indução da mionecrose pelo veneno bruto de $P$. paulista pode ser de responsabilidade da fosfolipase $A_{2}$, um dos principais componentes do veneno desta espécie de vespa (PaesOliveira, 2000).

Estudos posteriores com a fração fosfolipásica do veneno de P. paulista serão de grande importância para comprovar a efetiva participação dessa enzima na atividade miotóxica.

\section{REFERÊNCIAS}

1. ABE, T.; KAWAI, N.; NIWA, A. Purification and properties of a presynaptically acting neurotoxin, mandaratoxin, from hornet (Vespa mandarinia). Biochemistry. v. 21, p.1693-1697, 1982.

2. BANKS, B.E.C.; SHIPOLINI, R.A. In PIECK, T. Venoms of the Hymenoptera. London Academic Press, 1986, p.329-416.

3. BÜLBRING, E.F. Observations on the isolated phrenic nerve, diaphragm preparations of the rat. Brit. J. Pharmacol. v.1, p.38-61, 1946.

4. DOTIMAS, E.M.; HIDER, R.C, Honeybee venom. Bee World. v. 2, p.51-71, 1987.

5. DUNCAN, C.J. Role of intracellular calcium in promoting muscle damage: a strategy for controlling the dystrophic condition. Experientia. v. 34, p.1531-1540, 1978.

6. GOPALAKRISHNAKONE, P.; DEMPSTER, D.W.; HAWGOOD, B.J.; ELDER, H.Y. Cellular and mitochondrial changes induced in the structure of murine skeletal muscle of crotoxin, a neurotoxic phospholipase $\mathrm{A}_{2}$ complex. Toxicon. v. 22, p. 85-93, 1984.

7. GUTIERREZ, J.M.; ARROYO, O.; CHAVES, F.; LOMONTE, B.; CERDAS, L. Pathogenesis of myonecrosis induced by coral snake (Micrurus nigrocinctus) venom in mice. Br. J. Exp. Path. v. 67, p. 1-13, 1986.

8. HABERMANN, E. Bee and wasp venoms: The biochemistry and pharmacology of their peptides and enzymes are reviewed. Science.v. 177, p.314-322, 1972.

9. HARRIS, J.B.; JONSON, M.A.; KARLSSON, E. Pathological responses of rat skeletal muscle to a single subcutaneous injection of a toxin isolated from the venom of the Australian tiger snake, Notechis scutatus scutatus. Clin. Exp. Pharmac. Physiol.v. 2, p.383-395, 1975.

10. HARRIS, J.B.; MALTIN, C.A. Myotoxic activity of the crude venom and the principal neurotoxin, taipoxin, of the Australian taipan, Oxyuranus scutellatus. Br. J. Pharmac. v. 76, p. 67-73, 1982.

11. HARTREE, E.F. Determination of protein: Amodification of Lowry method that gives a linear photometric response. Anal. Biochem.v. 48, p.422-427, 1972.

12. HO, C.L.; KO, J.L. Hornetin: the letal protein of the hornet (Vespa flavitarsus) venom. FEBS letters. v. 209, p.18-22, 1986.

13 HOMMA, M.; TU, A.T. Morphology of local tissue damage in experimental snake envenomation. Br. J. Exp. Path. v. 52, p. 
538-547, 1971.

14. OLIVEIRA, M.R.; PALMA, M.S. Polybitoxins: a group of phospholipases $\mathrm{A}_{2}$ from the venom of the neotropical social wasp paulistinha (Polybia paulista). Toxicon. v.36, p.189-199, 1998.

15. OWNBY, C.L.; ODELL, G.V. Pathogenesis of skeletal muscle necrosis induced by Tarantula venom. Experimental and Molecular Pathology. v. 38, p.283-296, 1983.
16. PAES-OLIVEIRA, M.R. Efeitos do veneno bruto de Polybia (Mirapetra) paulista (Iehring, 1896) em camundongos. Estudos Bioquímico, farmacológico e morfológico. Rio Claro, 2000. 135p. Tese (Doutorado) - Universidade Estadual Paulista.

17. YASUHARA, T; NAKAJIMA, T; FUKUDA, K.; TSUKAMOTO, Y.; MORI, M.; KITADA, C.; FUJINO, M. Struture activity of chemotactic peptide from the venom sac of Vespinae. In: MUNEKATA, E. Peptide chemistry. Osaka, 1984. p.185-190. 